\title{
High helminthic co-infection in tuberculosis patients with undernutritional status in northeastern Ethiopia
}

\author{
Fikru Gashaww ${ }^{1,23^{*}}$, Samuel Bekele${ }^{1}$, Yalemtsehay Mekonnen², Girmay Medhin ${ }^{1}$, Gobena Ameni ${ }^{1}$ and Berhanu Erko
}

\begin{abstract}
Background: Tuberculosis and parasitosis are the widely distributed diseases in Ethiopia with the leading cause of mortality and morbidity, respectively. There has been no information on the status of co-infections of tuberculosis and parasitosis in Oromia Zone of Amhara Region and South Wollo, Ethiopia. Hence, this study primarily focuses on determining the status of tuberculosis and parasitosis co-infections and associated factors.

Methods: The study was conducted in Oromia Special Zone of the Amhara Regional State and South Wollo Zone, northeastern Ethiopia from April 2015 to January 2017. Tuberculosis cases confirmed by health personnel at the health institutions were the source of the study sample. In a cross-sectional study 384 smear positive pulmonary and extra-pulmonary tuberculosis cases were recruited. Faecal specimens provided by the study participants were examined for parasitic co-infections using direct saline microscopic test, Kato-Katz and concentration techniques. Nutritional status was determined using body mass index and mid-upper arm circumferences. Data were analyzed using descriptive statistical methods and Pearson chi-square.
\end{abstract}

Results: Tuberculosis and parasitosis co-infection prevalence was 10.8\%, and the proportion of intestinal helminths accounted for $9.7 \%$ while intestinal protozoa accounted for 1.9\%. Cases with single parasitic infection was $89.3 \%$ among co-infected individuals. Co-infection of both disease was not significantly associated with gender and age $(P>0.05)$. The prevalence of undernutrition was $58.6 \%$ as determined using body mass index and $73.0 \%$ as determined using mid-upper arm circumference with no significant association with gender. Among all forms of tuberculosis cases (384) screened for the study, the bacterial positivity was relatively more common in males (55.5\%) than females (44.5\%). Tuberculosis lymphadenitis was found to be the most prevalent (85.9\%) form of extrapulmonary tuberculosis with cervical adenopathy (75.3\%) being the commonly existing disease.

Conclusions: The rate of helminthic co-infection is predominantly high than that of intestinal protozoa. Single parasitic co-infection was more common than double or multiple co-infections. Both body mass index and midupper arm circumference anthropometric parameters revealed greater risk of undernutrition in tuberculosis patients. Thus, screening and prompt treatment of parasites in tuberculosis patients and a support of nutritional supplementation for malnourished tuberculosis patients should be further studied which might enhance the disease treatment and minimize the risk of its complexity.

Keywords: Tuberculosis, Parasitosis, Co-infection, Undernutrition, Northeastern Ethiopia

\footnotetext{
* Correspondence: fikrug2012@gmail.com

${ }^{1}$ Aklilu Lemma Institute of Pathobiology, Addis Ababa University, Addis

Ababa, Ethiopia

${ }^{2}$ Department of Microbial, Cellular and Molecular Biology, College of Natural

Sciences, Addis Ababa University, Addis Ababa, Ethiopia

Full list of author information is available at the end of the article
}

(c) The Author(s). 2019 Open Access This article is distributed under the terms of the Creative Commons Attribution 4.0 International License (http://creativecommons.org/licenses/by/4.0/), which permits unrestricted use, distribution, and reproduction in any medium, provided you give appropriate credit to the original author(s) and the source, provide a link to the Creative Commons license, and indicate if changes were made. The Creative Commons Public Domain Dedication waiver (http://creativecommons.org/publicdomain/zero/1.0/) applies to the data made available in this article, unless otherwise stated. 


\section{Multilingual abstracts}

Please see Additional file 1 for translations of the abstract into the five official working languages of the United Nations.

\section{Background}

Tuberculosis (TB) is the leading bacterial infectious diseases that cause profound mortality and morbidity throughout the world. It is a highly chronic unpardonable respiratory disease mainly affecting lungs and other body parts as extra-pulmonary tuberculosis (EPTB). The disease is primarily caused by Mycobacterium tuberculosis $(M t b)$ having an infection rate of over one-third of the global population [1]. Other members of the $M t b$ complex like M. bovis, M. africanum and M. microti can also cause human TB in rare cases [2]. In 2017, TB caused an estimated death of 1.6 million of which 0.3 million are those co-infected with HIV and the disease continuous as one of the top ten leading causes of mortality. Although there are some progress in Ethiopia in terms of reducing incident rate of $\mathrm{TB}$, the country still remains as one of the top 30 high $\mathrm{TB}$ burden countries [3].

It is also estimated that 3.5 billion of the global population are infected with intestinal parasites of whom 450 million are ill as a result of the infection [4]. These parasites are heterogeneous group of protozoa and helminths that live part or all of their lives in the hosts where they derive necessary nutrients, grow, and reproduce $[5,6]$. The parasites interfere with nutritional and immune profiles of an individual promoting secondary infections, such as $M t b$. Prevalence of intestinal parasitic infection is remarkably high in sub-Saharan African countries where TB is also common [5, 7-10].

Helminth infections can reactivate latent $\mathrm{TB}$ and aggravate the disease expression [11]. Limited epidemiological studies in Ethiopia have shown that chronic parasitic infection could increase the risk of TB [12-14]. Other conditions like Diabetes mellitus, malnutrition, and malignancies are also known to enhance the risk of TB infection $[15,16]$.

Identifying nutritional status of an individual could bring a substantial role in the prevention and control of the diseases. The relative risk of $\mathrm{TB}$ infection among persons in the lowest body mass index (BMI) category was more than five-fold higher compared to the group that fall in the highest BMI category [17]. Undernutrition affects cell-mediated immunity which is vital for the principal host defense mechanism against TB. The likelihood of developing primary or latent TB infection to active disease in undernourished group is greater [18]. This evidence supports the recommendation that patients with TB should be nutritionally assessed and get nutritional care and support which directs nutrition screening, assessment and management as an integral component of TB treatment and care [19].

As far as this study is concerned, parasitic co-infection and nutritional status of tuberculosis patients are not known in the study area. Thus, the study was primarily undertaken to determine the prevalence of parasitic coinfection and malnutrition among TB cases in Oromia Zone of Amhara Region, and South Wollo Zone. The findings are expected to contribute towards proper treatment and management of $\mathrm{TB}$ in the study area and beyond.

\section{Methods \\ Description of the study area}

The study was conducted in Oromia Special Zone of the Amhara Regional State and South Wollo Zone, northeastern Ethiopia. The area was selected purposely for this study that there was no any reported documents that shows the status of TB-parasitic co-infections and the associated factors. Both zones have administrative centers in Kemise and Dessie Towns. The former Town is the administrative center for the Oromia Special Zone since 1994 with a latitude of $10^{\circ} 43^{\prime} 27.4^{\prime \prime} \mathrm{N}$ and longitude of $39^{\circ} 52^{\prime} 24.03^{\prime \prime} \mathrm{E}$. The town is found at an altitude of $1446.88 \mathrm{~m}$ and a distance of $325 \mathrm{~km}$ northeast of Addis Ababa. On the other hand, Dessie Town is the capital of South Wollo Zone having a north latitude and east longitude of $11^{\circ} 8^{\prime}$ and $39^{\circ} 38^{\prime}$, respectively. Dessie has an average altitude of $2475.1 \mathrm{~m}$ and located $401 \mathrm{~km}$ northeast of Addis Ababa [20].

Administratively, the Oromia Special Zone has seven districts. Residents of the zone receive governmental health service from 27 health centers and one general hospital that partially began its function at Kemise Town in 2015. The two towns administration of Oromia Special Zone (Kemise and Bati) have one governmental health center each and were accessible for our pulmonary tuberculosis (PTB) sample collection. Similarly, South Wollo Zone has 18 districts and two town administration (Dessie and Kombolcha) (Fig. 1).

\section{Study population}

TB cases confirmed by the health personnel (pathologist, medical doctors, health officers, nurses and laboratory technologists) and those who fulfilled the inclusion criteria were included in the study. The samples (sputum, Fine-needle aspirates (FNAs) and stools) were collected on the spot from consenting participants until the expected sample size was achieved.

In addition, non-active TB cases using clinical symptoms (cough, sputum production, haemoptysis, dyspnea, anorexia, chest pain, fever, drenching night sweat, weight loss and weakness), apparently healthy individuals matched with TB cases by age (with a difference of +5 year), sex and 


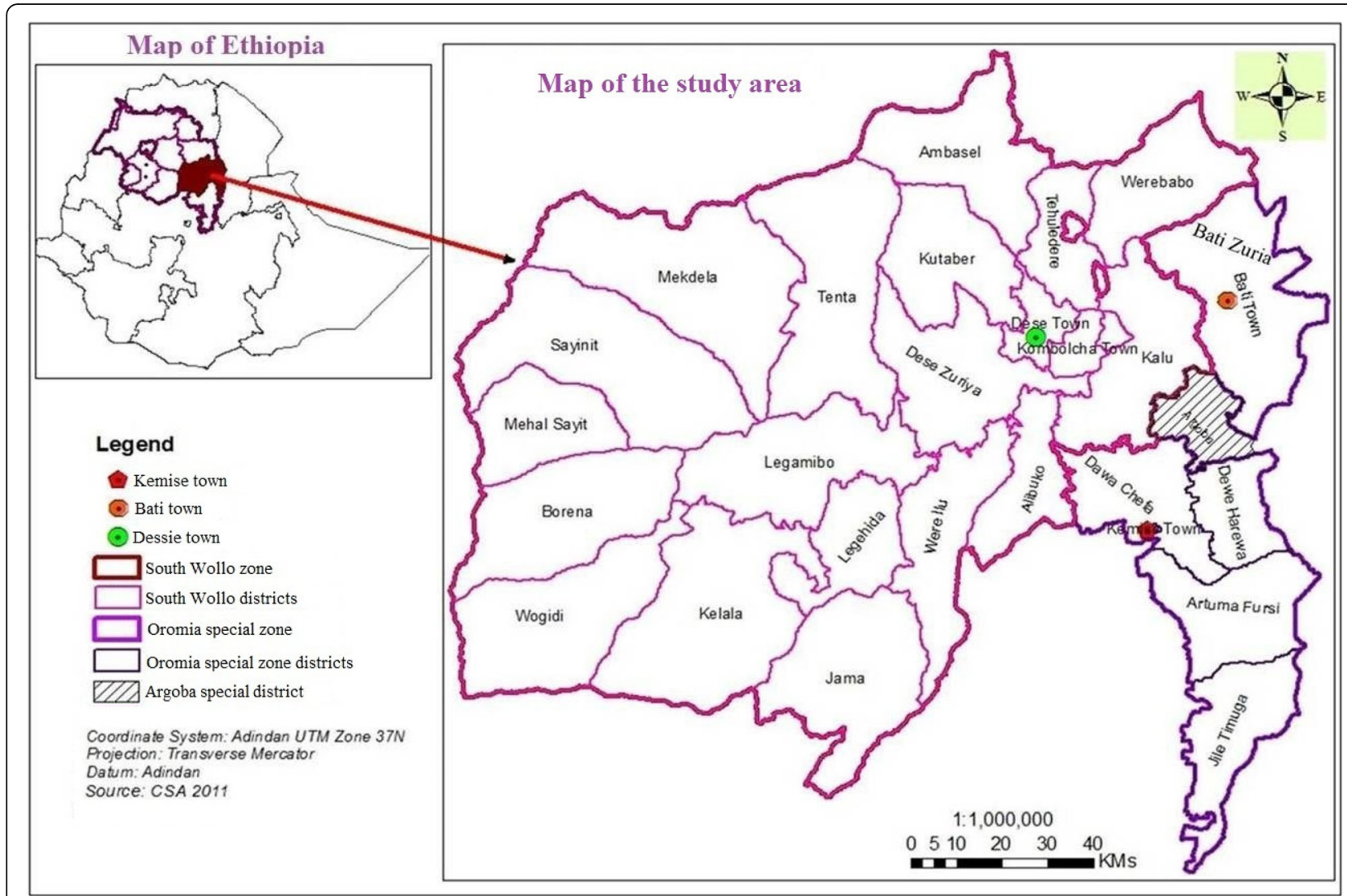

Fig. 1 Map of Ethiopia showing the catchment areas of the patients, April 2015 to January 2017

place of living were used as control to compare the nutritional status. The controls were not bacteriologically and parasitologically confirmed for TB and parasitosis, respectively. On the other hand, those individuals who came to the health facilities with the TB cases but didn't fulfill the indicated criteria were excluded.

All TB cases from April 2015 to January 2017 who were 18 years and older and willing to participate in the study based on their written voluntary consent were included. This is due to small proportion of TB cases younger than 18 years. Those with severe TB and unable to provide sputum, and those who gave their sputum for TB examination but couldn't provide faecal specimens were excluded from the study.

Preliminary survey was made for 3 months in all governmental health facilities of the seven districts in Oromia Special Zone. Based on the availability of samples (convenience sampling) and transportation access, the data were collected from Kemise and Bati Town health centers of the Special Zone. In addition, to get more TB cases Dessie Referral Hospital (DRH), Bikat Higher Diagnostic Laboratories (BHDL), Dessie Health Center (DHC) and Boru Meda Hospital (BMH) were also the sample collection sites from Dessie Town (Fig. 1). Clinically suspected and bacteriologically confirmed patients using sputum smear test in all study sites were included in the study. GeneXpert was additionally done for TB diagnosis at DRH. For EPTB, the suspected samples were collected and examined at BHDL by experienced pathologist.

\section{Sample size estimation}

Institution-based cross-sectional study design was performed. For determination of sample size, co-infection prevalence (33.3\%) of $M t b$ and intestinal parasitic infections (IPIs) in northwest Ethiopia [13], 95\% confidence in the estimate and 5\% margin of error were considered. This resulted in a sample size of 341 smear positive TB cases. To compensate for the non stool providing TB cases, inadequate sputum specimen for culture and to have better coverage of the study population an additional $12.6 \%$ of the minimum sample size was considered and the final sample size was calculated as 384 .

\section{Sample collection and processing}

Dry, translucent, leak-proof $50 \mathrm{ml}$ capacities of falcon tubes were used to collect a minimum of 3-5 ml sputum sample from $\mathrm{BMH}$ where drug resistant $\mathrm{TB}$ cases were handled and treated. Similarly, a $30 \mathrm{ml}$ sputum cup was used for sputum collection from the rest of the study 
sites. The data were safely recorded on the spot of sample collection to determine the patients' and control group socio-demographic characteristics.

Direct microscopic examination of the sputum was done by fluorescent microscope (FM) at a magnification of $200 \times$. The bacterial grading scale was considered as negative when no AFB (acid fast bacillus)/in at least 30 fields, scanty (1-29 AFB/30 fields), 1+ (30-299 AFB/30 fields), $2++(10-99 \mathrm{AFB} /$ in at least 15 fields) and $3+++$ (>100 AFB/field in at least 6 fields). Positive specimens from patients were kept at a range of -10 to $-20^{\circ} \mathrm{C}$ refrigerator until being transported to Aklilu Lemma Institute of Pathobiology (ALIPB) for culturing following the protocol described elsewhere [21].

FNA samples from patients suspected for EPTB was collected using a 21-gauge needle attached to a $10 \mathrm{ml}$ syringe with maximum care and safety by an experienced pathologist [22]. Afterwards, the Ziehl-Neelsen smear technique was performed by the same pathologist to check its positivity. From positive participants of the smear, a suction of about $1 \mathrm{ml}$ samples were collected for this research purpose and preserved in sterile and tightly closed nunc tubes with phosphate buffer saline of $1 \mathrm{ml}$ at $\mathrm{pH} 7.2$ and kept in the same refrigerator [23, 24]. Finally, both sputum and FNA samples were transported from temporary storage site of the health institutions in a cold chain of $4{ }^{\circ} \mathrm{C}$ to TB laboratory of ALIPB in Addis Ababa. At ALIPB the samples were kept in a deep freezer of $-80^{\circ} \mathrm{C}$ until culturing was done [25].

\section{Lowenstein-Jensen (LJ) media preparation and mycobacterial culturing}

A stock of selective LJ media was used for the preparation of Mycobacterium culture based on the manufacturer's instruction (Fluka Chemie $\mathrm{GmbH}$, Switzerland) and the standard operating procedure of TB laboratory at ALIPB. Glycerol (0.75\%) and pyruvate $(0.6 \%)$ was added to enrich the media for the cultivation of $M t b$ and $M$. bovis, respectively. The prepared media were left for $48 \mathrm{~h}$ to check for contamination before culturing the bacteria. Poor quality media were also identified and discarded. All the inoculated LJ slants in culture tubes were incubated aerobically at $37^{\circ} \mathrm{C}$ in a slanted position and contamination was checked daily for the first week. The inoculated media were placed in an upright position starting from the second week and colony formation was checked for eight consecutive weeks. For weakly grown colonies, sub-culturing of the colony was done in another new medium [26].

\section{Parasitological examination}

Faecal specimens were collected using stool cup with a tight fitting lid and two applicator sticks given to the TB patients to bring a sizable stool sample of his/her own.
The slides were labeled with identification number and a drop of saline $(0.9 \%)$ was placed at the middle for direct wet mount faecal examination. A small proportion (about a match stick size) of the specimen was picked up and mixed with the saline and covered with cover slip for entire microscopic observation under low power objective. A single Kato-Katz thick smear per stool sample was also prepared from the stool using a template delivering $41.7 \mathrm{mg}$ of feces. A multiplication factor of 24 was used to convert egg count into eggs per gram of stool [27]. A portion of the fresh stool samples (about 1 g) preserved in $10 \mathrm{ml}$ sodium acetate-acetic acidformalin (SAF) solution was transported to Medical Parasitology Laboratory of Aklilu Lemma Institute of Pathobiology and processed using saline ether concentration techniques for microscopic examination. Lack of repeated stool examination for parasite test in this study was considered as a limitation of the study.

\section{Anthropometric measurements}

Age, sex, height, weight and mid-upper arm circumference (MUAC) were measured and recorded. The BMI of participants was calculated from individuals' weight in kilograms and height measured in meters to one decimal place using calibrated measurements. In BHDL, measurements for BMI were also done using calibrated ultrasonic height and weight measuring machine. The print outs of the machine were collected and registered for each of the participants. The result was categorized as underweight $\left(\mathrm{BMI} \leq 18.5 \mathrm{~kg} / \mathrm{m}^{2}\right)$, normal $\left(18.5 \mathrm{~kg} / \mathrm{m}^{2}<\right.$ BMI $\left.\leq 25 \mathrm{~kg} / \mathrm{m}^{2}\right)$, overweight $\left(25 \mathrm{~kg} / \mathrm{m}^{2}<\mathrm{BMI} \leq 30 \mathrm{~kg} / \mathrm{m}^{2}\right)$, and obese (BMI $>30 \mathrm{~kg} / \mathrm{m}^{2}$ ). Weighing of the participants was made to the nearest $0.1 \mathrm{~kg}$ and the proportion of mildly (BMI $\left.17.0-18.5 \mathrm{~kg} / \mathrm{m}^{2}\right)$, moderately $\left(16.0 \mathrm{~kg} / \mathrm{m}^{2}-16.9 \mathrm{~kg} / \mathrm{m}^{2}\right)$ and severely (BMI $\left.<16.0 \mathrm{~kg} / \mathrm{m}^{2}\right)$ undernourished participants identified [28, 29]. Mid-upper arm circumference was measured to the nearest $0.1 \mathrm{~cm}$ and also used for the assessment of malnutrition. Considering the cutoff values for MUAC, the study participants were categorized as undernourished when MUAC is $\leq 23 \mathrm{~cm}$ for males and $\leq 22 \mathrm{~cm}$ for females $[30,31]$.

\section{Quality control}

Questionnaire was prepared in English and then translated into the local languages (Amharic and Afaan Oromo) by an expert who was fluent in both languages to maintain its consistency. Training was given for data collectors and supervisors. Pre-testing of the questionnaire was made on 30 study participants for its clarity and appropriateness which was latter included in the study. Data collection process was strictly followed day to day by the supervisor and principal investigator. In addition, quality of reagents and instruments was checked by experienced laboratory technicians using 
negative and positive control slides. Each of the specimens was done by two experienced laboratory technicians. In cases where the results were discordant, a third reader was used whose result was considered as the final result. Continuous quality control of the health institutes was also made by Dessie regional laboratory experts as an external quality assurance. In addition to the trainings on BMI measurements, the instruments were also calibrated for the research work.

\section{Data management and analysis}

The recorded data was checked for completeness and consistency, and then entered into Microsoft Excel 2007 spreadsheets. This data was then exported to IBM SPSS Statistics for Windows, Version 25.0. (Armonk, NY: IBM Corp., USA) program for analysis. Percentage and mean were used to descriptively summarize the data. Association of TB-parasitosis co-infection and malnutrition with gender and age was analyzed using chi-square. Differences were considered significant at a $P$-value of $<$ 0.05 .

\section{Results}

Socio-demographic characteristics and tuberculosis infections

A total of $384 \mathrm{~TB}$ cases (213 males and 171 females) were involved in the study. Most of the cases were recruited from South Wollo Zone $(n=247)$. Their age ranged from 18 to 75 years with a mean age of 33.7 $(\mathrm{SD}=12)$ having no significant difference between males $($ mean $=34.5, \mathrm{SD}=12.3)$ and females $($ mean $=32.7, \mathrm{SD}=$ 11.4). The average household size of the TB cases was 4.4. Pulmonary TB cases accounted for $74.5 \%(286 / 384)$, the overall prevalence of TB was highest $(67.0 \%)$ in the $18-37$ years age group and those with family size ranging from 3 to 5 were more affected (Table 1).

\section{Mycobacterium tuberculosis -parasite co-infections}

A total of 259 faecal samples (142 males and 117 females) were collected and examined. The remaining tuberculosis cases refused to give faecal specimens and some of them were also severely sick and did not provide specimen. From the study, comparable intestinal parasitic infection was found among pulmonary $\mathrm{TB}$ cases $(10.5 \%, 19 / 181)$ and extra-pulmonary ones $(11.5 \%$, 9/78) (Fig. 2).

The overall $M t b$-parasite co-infection was $10.8 \%$ (28/ $259)$. From the total co-infected cases, $89.3 \%(25 / 28)$ had single parasitic infection, while $7.1 \%(2 / 28)$ had double infection, and $3.6 \%(1 / 28)$ had four infections. The infection of intestinal helminths accounted for $9.7 \%$ and those of intestinal protozoa accounted for $1.9 \%$. Although there was greater helminthic co-infection than protozoa co-infection among tuberculosis patients in the
Table 1 Background characteristics of tuberculosis patients recruited from health institutes of Oromia Special Zone and South Wollo Zone, northeastern Ethiopia, April 2015 to January 2017

\begin{tabular}{|c|c|c|}
\hline Characteristics & Number & Percent \\
\hline \multicolumn{3}{|l|}{ Sex $(n=384)$} \\
\hline Male & 213 & $55.5 \%$ \\
\hline Female & 171 & $44.5 \%$ \\
\hline \multicolumn{3}{|l|}{ Age in years $(n=371)$} \\
\hline $18-27$ & 133 & $35.8 \%$ \\
\hline $28-37$ & 116 & $31.3 \%$ \\
\hline $38-47$ & 68 & $18.3 \%$ \\
\hline$\geq 48$ & 54 & $14.6 \%$ \\
\hline \multicolumn{3}{|l|}{ Marital status $(n=333)$} \\
\hline Single & 116 & $34.8 \%$ \\
\hline Married & 185 & $55.6 \%$ \\
\hline Divorced & 32 & $9.6 \%$ \\
\hline \multicolumn{3}{|l|}{ Family size $(n=323)$} \\
\hline$<3$ & 65 & $20.1 \%$ \\
\hline $3-5$ & 161 & $49.9 \%$ \\
\hline$\geq 6$ & 97 & $30.0 \%$ \\
\hline \multicolumn{3}{|l|}{ Occupation ( $n=345)$} \\
\hline Government employed & 29 & $8.4 \%$ \\
\hline Merchant & 57 & $16.5 \%$ \\
\hline Farmer & 138 & $40.0 \%$ \\
\hline Daily laborer & 31 & $9.0 \%$ \\
\hline No job/unemployed & 40 & $11.6 \%$ \\
\hline Student & 26 & $7.5 \%$ \\
\hline Others $^{a}$ & 24 & $7.0 \%$ \\
\hline \multicolumn{3}{|l|}{ Religion $(n=348)$} \\
\hline Christian & 119 & $34.2 \%$ \\
\hline Muslim & 229 & $65.8 \%$ \\
\hline \multicolumn{3}{|l|}{ Ethnicity $(n=346)$} \\
\hline Amhara & 295 & $85.3 \%$ \\
\hline Oromo & 46 & $13.3 \%$ \\
\hline Others $^{b}$ & 5 & $1.4 \%$ \\
\hline \multicolumn{3}{|l|}{ Educational status $(n=347)$} \\
\hline Illiterate (unable to read and write) & 154 & $44.4 \%$ \\
\hline Primary (Grade 1-8) & 99 & $28.5 \%$ \\
\hline Secondary (Grade 9-12) & 61 & $17.6 \%$ \\
\hline Above secondary (Grade > 12) & 33 & $9.5 \%$ \\
\hline
\end{tabular}

${ }^{\mathrm{a}}$ Housewife/catering/pensioner/casher, ${ }^{\mathrm{b}}$ Tigre/Afar

study area, the difference was not statistically significant $\left(\chi^{2}=6.000, \mathrm{df}=4\right.$ and $\left.P=0.199\right)$.

Schistosoma mansoni infection was the most prevalent parasitic co-infection (4.25\%), followed by Ascaris lumbricoides (2.32\%). Trichuris trichiura, Enterobius vermicularis 


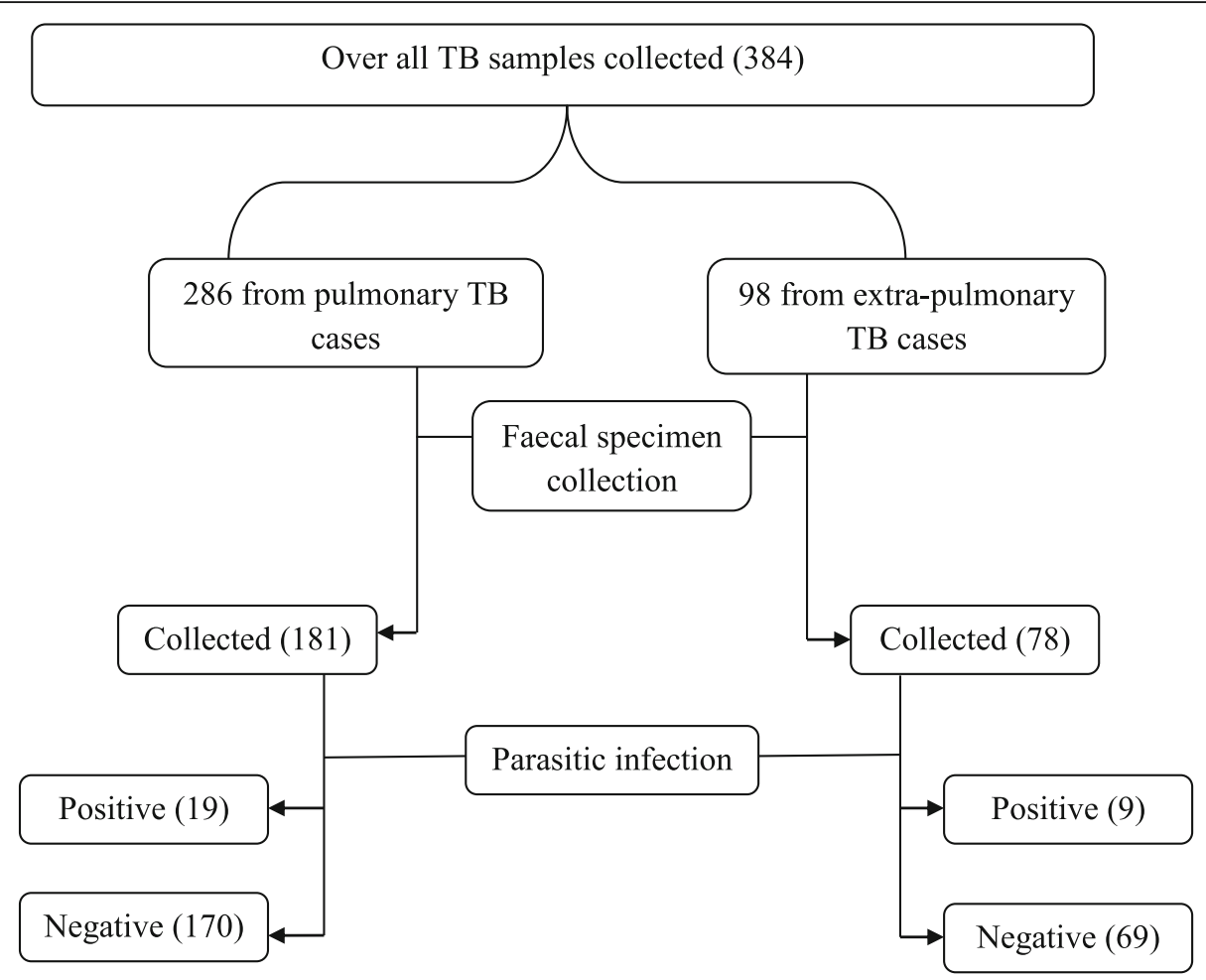

Fig. 2 A flowchart outlining the general procedure of sample collection and TB-parasitic co-infections

and Hymenolepis nana were the other helminthic coinfections whereas Entamoeba histolytica/dispar and Giardia lamblia cysts were the only detected protozoan parasitic co-infections (Table 2).

The association of TB-parasite co-infection between males $(60.7 \%, 17 / 28)$ and females $(39.3 \%, 11 / 28)$ was not statistically significant $\left(\chi^{2}=439, \mathrm{df}=1\right.$ and $\left.P=0.507\right)$. Similarly, significant difference of $M t b$-parasitic co-

Table 2 Parasite species among tuberculosis cases in Oromia Special Zone and South Wollo, northeastern Ethiopia, April 2015 to January 2017

\begin{tabular}{ll}
\hline Types of parasites & $\begin{array}{l}\text { Number (percentage) } \\
\text { of infection }\end{array}$ \\
\hline Schistosoma mansoni & $11(4.3 \%)$ \\
Ascaris lumbericoides & $6(2.3 \%)$ \\
Trichuris trichiura & $2(0.8 \%)$ \\
Enterobius vermicularies & $2(0.8 \%)$ \\
Giardia lamblia & $2(0.8 \%)$ \\
Entamoeba histolytica/dispar & $1(0.4 \%)$ \\
Hookworm & $1(0.4 \%)$ \\
Schistosoma mansoni and Giardia lamblia & $1(0.4 \%)$ \\
Ascaris lumbericoides and Enterobius & $1(0.4 \%)$ \\
vermicularies & \\
Schistosoma mansoni, Hymenolepis nana, Giardia & $1(0.4 \%)$ \\
lamblia and hookworm & \\
Total & $28(10.8 \%)$ \\
\hline
\end{tabular}

infection was also not observed across different age groups $\left(\chi^{2}=36.238, \mathrm{df}=40\right.$ and $\left.P=0.640\right)$.

\section{Assessment of nutritional status}

The overall mean BMI of TB cases was $18.2 \mathrm{~kg} / \mathrm{m}^{2}$. Among the study participants $(50.0 \%, 192 / 384)$ had chronic energy deficiency, $34.6 \%$ (133/384) were normal and data was missing for $15.4 \%$ (59/384). Of the chronic energy deficient TB cases, $61.5 \%$ (118/192) were mildly undernourished, $21.9 \% \quad(42 / 192)$ were moderately undernourished and $16.7 \%(32 / 192)$ were severely undernourished.

Of 237 TB cases whose faecal specimens were examined, $58.6 \%(n=139)$ were underweight and there was no significant difference $(P=0.821)$ in the mean body mass index of TB-parasitic co-infected cases $($ mean $=18.1, \mathrm{SD}=1.3)$ and TB positive cases without parasitic co-infection (mean = 18.2, $\mathrm{SD}=2.1$ ). The BMI of co-infected cases didn't differ significantly from those of non-co-infected cases at different age groups $\left(\chi^{2}=4.601, \mathrm{df}=3\right.$ and $\left.P=0.203\right)$ and sex $\left(\chi^{2}=\right.$ $0.527, \mathrm{df}=1$ and $p=0.468$ ).

Among smear positive TB cases whose MUAC were measured, $72.8 \%(205 / 281)$ of them were undernourished and was not significantly associated with gender $\left(X^{2}=0.831, \mathrm{df}=1\right.$ and $\left.P=0.362\right)$. When MUAC was used to determine nutritional status, $6.4 \%$ of the undernourished TB cases and $2.1 \%$ of the normal nourished TB cases had parasitic co-infection showing non- 
significant association $\left(\chi^{2}=0.056, \mathrm{df}=1\right.$ and $\left.P=0.813\right)$. As a whole, significant difference was not observed between TB parasitosis co-infections and nutritional status of the TB cases (Table 3).

Considering our matched criteria set in the methodology part, 86 participants (55 males and 31 females) were used as control groups. The difference between the nutritional status of smear positive TB cases $($ mean $=$ 21.4, $\mathrm{SD}=2.0)$ and the control groups $($ mean $=22.9$, $\mathrm{SD}=2.5)$ was statistically significant $(P=0.029)$ as MUAC parameter was used. However, it is not statistically significant $(P=0.220)$ when body mass index is considered with average mean $(+\mathrm{SD})$ of $18.2(+1.95)$ and $20.7(+2.73)$ for $\mathrm{TB}$ cases and the control groups, respectively.

\section{Mycobacterium culture result}

Growth was observed in $29.2 \%(n=112)$ samples after culturing all the smear and GeneXpert positive samples on LJ media. Culture positivity was not significantly different as compared to bacterial load under laboratory examination of smear test in both fluorescent microscope (FM; $P=0.455)$ and GeneXpert $(P=0.427)$. Thirty six samples had missed grading scale (MGS) of the bacterial load (Fig. 3).

Among the EPTB cases, site of infection was detected in 85 participants by the pathologist and TB lymphadenitis (TBLNs) was the most prevalent $85.9 \%$ (73/85). Of these TBLNs cervical adenopathy $75.3 \%(55 / 73)$ was the most frequently occurring disease. Of the suspected smear positive EPTB samples, $18.4 \%$ were culture positive (Table 4).

\section{Discussion}

In this study, it has been observed that as family size increased the risk of TB transmission in the community also increased. This might be due to the high risk of contact. Higher rate of infection in farmers and those who cannot read and write might be due to lack of awareness about the disease prevention, immediate diagnosis and treatment $[13,14]$.
Prevalence of $M t b$ parasitic co-infection in this study $(10.8 \%)$ is less than the recent co-infection rate $(22 \%)$ reported from Addis Ababa [32]. This is also true with the higher $M t b$ intestinal parasitic co-infection prevalence rate reported from other parts of Ethiopia in Gondar (33.3\%) and Arba Minch (26.3\%) [13, 14]. Such greater co-infection rate in other study sites of Ethiopia as compared to the recent finding might be due to the difference in geographical settings and the study participants. The age group of the study participants also vary in that only those whose age were 18 years and older were considered in this study whereas in the case of the former studies those who were younger than 18 were included. Studies in the country revealed that lower age groups possess higher parasitic infection than the older age groups [33]. As there is no gold standard test for parasitic stool examination, differences in the testing mechanisms (direct saline, SAF and Kato-Katz) might also be another factor for the variations of TB parasitic coinfection since the sensitivity of one diagnostic method is different from the other [34].

Similar to this study, findings in Arba Minch showed that the prevalence of intestinal helminth infections was greater $(24.4 \%)$ than that of intestinal protozoa (6.1\%) [14]. Comparable studies toward $M t b$ parasitic coinfection in northwestern Ethiopia also found 44.5 and $7.6 \%$ as the proportion of helminthic and protozoa infection, respectively [13]. Although helminthic infection is high in both of the study cases, their percentage varies as compared to this study which might be due to the difference in study subjects as well as the study sites. Contrary to the overall high prevalence of $A$. lumbericoides infection in the country, our finding showed $S$. mansoni to be the most widespread helminthic infections followed by A. lumbericoides. This is considered as due to high prevalence and endemicity of schistosomiasis in Oromia Special Zone specifically in Bati and Kemise areas of the study site $[35,36]$.

Although there was no significant difference in parasitic co-infections among male and female study participants, males were infected in a greater proportion than

Table 3 Nutritional status and parasitic co-infection of tuberculosis cases in Oromia Special Zone and South Wollo, northeastern Ethiopia, April 2015 to January 2017

\begin{tabular}{|c|c|c|c|c|c|c|}
\hline & \multicolumn{3}{|c|}{ Nutritional status using MUAC } & \multicolumn{2}{|c|}{ Nutritional status using BMI } & \multirow[t]{2}{*}{$P$-value } \\
\hline & Normal n (\%) & Under-nourished $n(\%)$ & $P$-value & Normal $n(\%)$ & Under-nourished $n(\%)$ & \\
\hline \multicolumn{7}{|l|}{ Sex } \\
\hline Males & $38(24.8)$ & $115(75.2)$ & 0.362 & $57(43.8)$ & $73(56.2)$ & 0.390 \\
\hline Females & $38(29.7)$ & $90(70.3)$ & & $41(38.3)$ & $66(61.7)$ & \\
\hline \multicolumn{7}{|l|}{ Co-infection status } \\
\hline Co-infected & $6(25.0)$ & $18(75.0)$ & 0.813 & $8(30.8)$ & $18(69.2)$ & 0.246 \\
\hline Not co-infected & $70(27.2)$ & $187(72.8)$ & & $90(42.7)$ & $121(57.3)$ & \\
\hline
\end{tabular}

MUAC Mid-upper arm circumference, BMI Body mass index. 


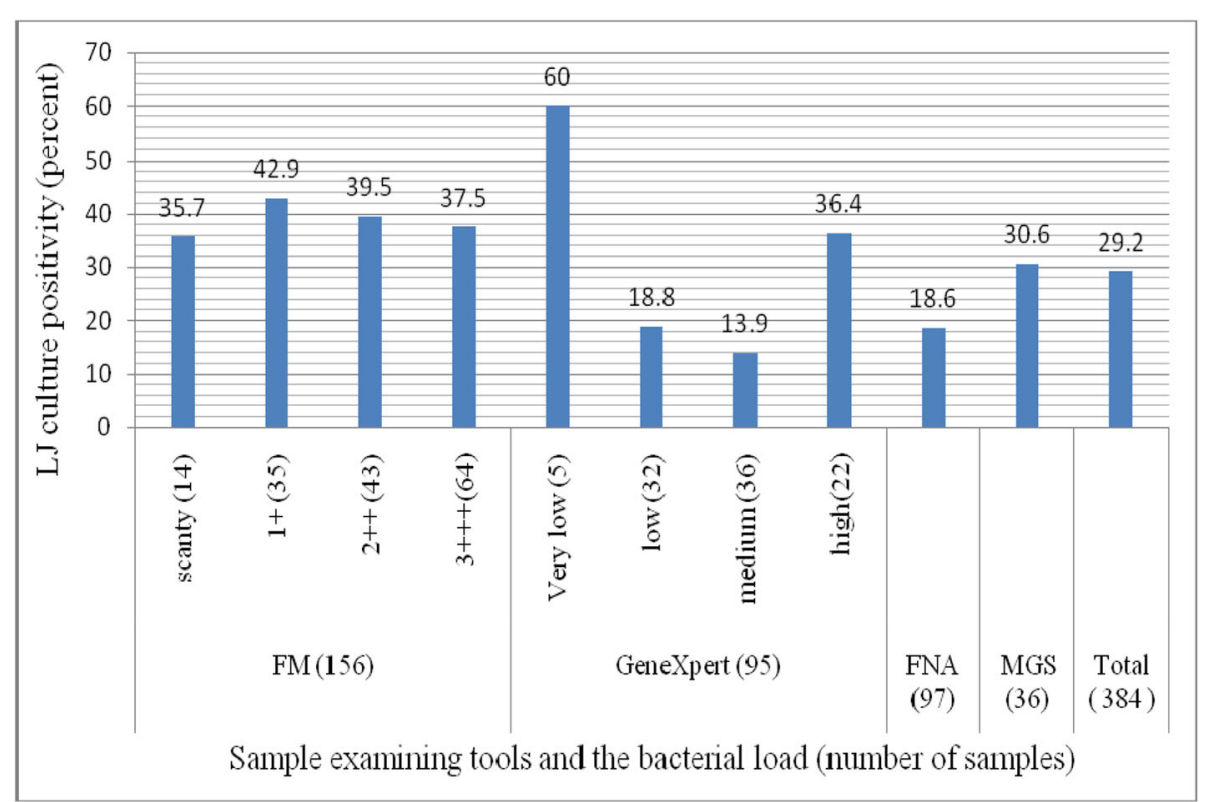

Fig. 3 Comparison of results of smear microscopy (FM \& FNA) and GeneXpert with bacterial growth on $\sqcup$ medium, Oromia Special Zone and South Wollo, northeastern Ethiopia, April 2015 to January 2017. FM: Fluorescent microscope. FNA: Fine-needle aspirates. MGS: Missed grading scale. EPTB: Extra-pulmonary tuberculosis. LNs: Lymphadenitis

females similar to the former finding in northwest Ethiopia [13]. By contrast, a report from China showed that females are 2.05 times more likely to acquire IPIs than males [37]. Such differences between Ethiopia and China might be due larger number of males than females in the former and the reverse in the later country.

Several conditions including undernutrition, smoking, Diabetes mellitus and co-infections are important risk factors that aggravate the progress of $\mathrm{TB}[15,16]$. To these effects, our assessments of nutritional status among TB cases using BMI showed about half of the cases were under chronic energy deficiency. Similar studies in other two areas of Ethiopia (Addis Ababa: 39.7\% and Arba Minch: 33.3\%) found lower percentages as compared to this finding which might be due to the difference in time of taking the measurements $[15,38]$. In this study, measurements were taken on the spot of TB screening period when the patients' body mass is expected to be low. However, the measurements of body mass were taken during the follow up of drug therapy both in Addis Ababa and Arba Minch study cases when their body mass might be improved due to the follow up treatments. In fact, studies in Ghana (51\%) and urban Tanzania (56.8\%) reported closer prevalence of undernutrition to this finding in $M t b$ parasitic co-infected patients. In all indicated studies, mild malnutrition was at its highest peak than moderate and severe malnutrition [38-40].

The higher percentage (58.6\%) of undernutrition in $M t b$ parasitic co-infected cases in this study than

Table 4 Site of extra-pulmonary tuberculosis infection and the number of culture positives from BHDL, Oromia Special Zone and South Wollo, northeastern Ethiopia, April 2015 to January 2017

\begin{tabular}{lll}
\hline Site of EPTB infections & Number of infected cases (\%) & Number of culture positives (\%) \\
\hline Cervical LNs & $55(56.1)$ & $8(14.5)$ \\
Axilary LNs & $8(8.2)$ & $2(25.0)$ \\
Supraclavicular LNs & $6(6.1)$ & $1(16.7)$ \\
Other LNs ${ }^{a}$ & $4(4.0)$ & - \\
Non LN infections & $12(12.2)$ & $4(33.3)$ \\
Not sited (missed) & $13(13.3)$ & $3(23.1)$ \\
Total & $98(100.0)$ & $18(18.4)$ \\
\hline
\end{tabular}

anguinal, Submandibular and Anterior neck LNs

BHDL Bikat Higher Diagnostic Laboratories, EPTB Extra-pulmonary tuberculosis, LNs Lymphadenitis. 
parasite free TB cases (41.4\%) could imply that coinfection had an impact on the nutritional status of TB cases. Measurements using MUAC also confirmed the findings of $\mathrm{BMI}$ in similar way that greater percentage of the TB cases with parasitic co-infection were undernourished than those of non-coinfected cases. Such greater rate of undernourishment in co-infected cases might be due to the parasitic impact. Similar finding of nutritional assessment using both BMI and MUAC parameter suggests co-infection have an impact on the nutritional status of $\mathrm{TB}$ cases [32, 41]. In addition, implication of nutritional status difference among TB cases and the control group using both BMI and MUAC may be attributable to tuberculosis. This weight loss agrees with the clinical symptoms criteria for screening tuberculosis cases [24].

The extent of EPTB in Ethiopia is much higher (33\%) than the global average (15\%) [24]. This finding (25.3\%) also agrees with the report which might be due to diagnostic challenges including shortage of pathologists to identify and treat the cases on time in most health institutions. There was no any pathologist to diagnose EPTB in all governmental health institutes including the referral hospital where this study was done. Because of this, all the suspected cases were referred to a single private diagnostic laboratory (BHDL) and remained as the diagnostic challenge of the area.

The overall LJ culture positivity was confirmed in $29.2 \%(112 / 384)$ which is close to the study in Addis Ababa $(32.2 \%, n=124)$ [42]. On the contrary, the culture positivity of this study is much less than many studies whose findings were 95.9\% (118/123), 87.9\% (297/338), $53.5 \%(46 / 86)$ and $69.2 \%$ (63/91), respectively [43-46]. The less proportion of this study might be due to the delay of culturing time, electric interruption when the specimens were preserved in the refrigerator at the study sites and long distance travel from temporarily stored collection site to ALIPB where the specimens were cultured. These factors increase the chance of bacterial death in the collected sputum samples. Perhaps, it could also be our expectation that bacterial culture positivity might decrease as the sample stayed in the refrigerator for a long duration than immediate culturing.

Regarding both pulmonary and EPTB culturing results, of 286 pulmonary and 98 extra-pulmonary smear positive specimens, $94(32.8 \%)$ and $18(18.4 \%)$ were culture positive, respectively. This proportion is less than that of a study in India who found 329 (61.5\%) and 19 (29.2\%) as culture positive for $M t b$ in both pulmonary and EPTB cases in that order [47]. A study from different study areas in Ethiopia also reported greater culture positivity of both clinically manifested smear positive pulmonary (79\%, 756/953) and extra-pulmonary (38\%, 456/1198) TB [24]. Similar studies in northwestern Ethiopia and
Addis Ababa showed culture positivity of EPTB as 29.8 and $32.5 \%$, respectively $[48,49]$. In all instances, there is less culture positivity of EPTB than pulmonary ones which might be due to cytological suspicion of the specimen by pathologist unlike the detection of disease causative organism itself as in the case of PTB. Moreover, the suspected Mycobacteria cellular infection could be paucibacillary which decrease the sensitivity of diagnostic test in EPTB.

The EPTB has different manifestations based on the organs to be attacked and its intent of dissemination in the body. Similar to other relevant studies in the country, this finding also revealed that lymph nodes as the leading organs affected. In fact, the percentage of their infection rate differs as cervical, auxiliary, inguinal, supra-clavicular, sub-mandibular and anterior neck lymph nodes [24, 49]. This higher infection of lymph node is similar to the study reported from Germany [50]. On the other hand, the most common sites involved were the bone/joints and lymph nodes in United States of America [51], whereas the genitourinary system and skin were the common sites of infection reported from Hong Kong [52]. These differences may be attributable to either host or pathogen related factors as well as access to patient sample collection in the clinical settings.

Cervical lymph nodes were found as the most frequently infected anatomical site similar to other report from Ethiopia [53]. Such higher infection rate might be due to the physical proximity of lymph node to the route of infection where the bacilli can easily be picked up by macrophages or dendertic cells that facilitate the transportation of the bacilli in the cervical lymph nodes causing pathology. It could also be expected that the bacteria could easily spread from intra-thoracic lymphatics to the cervical areas. Limitations of this study include examination of a single faecal specimen, that faecal examination was not done for $32.5 \%$ of TB patients, that no sputum and faecal examination was done for the control groups and that a small number of participants fulfilled our matched criteria. All these might have a potential bias for the study and should be taken into consideration for future studies.

\section{Conclusions}

In the present study, there is relatively higher helminthicTB co-infection than those of protozoa parasites. Most of the TB cases in the study were found as undernourished. The prevalence of extra-pulmonary tuberculosis was found as in a greater proportion with cervical lymphadenitis as the principal infection site. Thus, parasitic coinfections and nutritional status of tuberculosis cases should be further studied by treating the parasites and improving nutritional status of the co-infected patients. 


\section{Supplementary information}

Supplementary information accompanies this paper at https://doi.org/10. 1186/s40249-019-0600-2.

Additional file 1. Multilingual abstracts in the five official working languages of the United Nations

\section{Abbreviations}

AFB: Acid fast bacillus; ALIPB: Aklilu Lemma Institute of Pathobiology; BHDL: Bikat Higher Diagnostic Laboratories; BMH: Boru Meda Hospital; BMI: Body mass index; DHC: Dessie Health Center; DRH: Dessie Referral Hospital; EPTB: Extra-pulmonary tuberculosis; FM: Fluorescent microscope; FNAs: Fine-needle aspirates; IPIs: Intestinal parasitic infections; LJ: LowensteinJensen; LNs: Lymphadenitis; Mtb: Mycobacterium tuberculosis; MUAC: Midupper Arm Circumference; PTB: Pulmonary tuberculosis; SAF: Sodium acetate-acetic acid-formalin; TB: Tuberculosis; TBLNs: TB lymphadenitis

\section{Acknowledgments}

We thank the zonal and districts health bureau of Oromia Special Zone and South Wollo Zone in Amhara region who gave us permission to do the research under their health institutes. All health institutes of the sample collection sites are duly acknowledged for their primary identification and diagnosis of TB cases. We are grateful to Dr. Zewditu Chanyalew (pathologist) for suction of EPTB samples in BHDL. Mr. Endalkachew Tedla of $\mathrm{BHDL}$ is also appreciated for giving us refrigerator and managing the overall activities of the laboratory work. All study participants are duly acknowledged for being part of this study. At last but not least, we thank Ms. Baysasu Gebre-Medhin for parasitic identification and all TB laboratory staff members of ALIPB for their technical support while culturing the mycobacteria.

\section{Authors' contributions}

FG, BE, GA, GM and YM conceived the idea and designed the study. FG, GA $\mathrm{BE}$ and $\mathrm{YM}$ coordinated sample collection. FG, BE, GA and SB carried out the laboratory analysis. FG, GM and BE did data analysis and interpretation. FG drafted the manuscript, and BE, GM, GA and YM reviewed and edited the manuscript. All authors read and approved the final manuscript.

\section{Funding}

This work was supported by funds from AAU thematic research project A/C 0162230106072100101. In addition, it was also supported in part by the $\mathrm{NIH}$ / Fogarty International Center Global Infectious Diseases grant D43TW009127 through H3 Africa.

\section{Availability of data and materials}

The datasets supporting the conclusions of this article are included within the article.

All data generated or analyzed during this study are included in this published article.

\section{Ethics approval and consent to participate}

The study was carried out after obtaining Ethical clearance from Ethical Review Board (Ref. No. CNSDO/392/07/15) of College of Natural and Computational Sciences, Addis Ababa University. Letter of permission was also obtained from health bureau of the study sites. Written informed consent was obtained from the study subjects. TB positive participants were referred to DOTs program for possible treatment. Drugs for treatment of parasitic co-infected patients were given free of any charge at the health institutions. The cost of payment was covered by the thematic research project entitled Mycobacterial Infections in Selected Rural Communities of Ethiopia and Their Animals, AAU. No other additional cost or economic incentive was given for the participants.

\section{Consent for publication}

Not applicable.

\section{Competing interests}

The authors declare that they have no competing interests.

\section{Author details}

Aklilu Lemma Institute of Pathobiology, Addis Ababa University, Addis Ababa, Ethiopia. ${ }^{2}$ Department of Microbial, Cellular and Molecular Biology, College of Natural Sciences, Addis Ababa University, Addis Ababa, Ethiopia. ${ }^{3}$ Department of Biology, College of Natural and Computational Sciences, Kotebe Metropolitan University, Addis Ababa, Ethiopia.

\section{Received: 27 April 2019 Accepted: 20 September 2019}

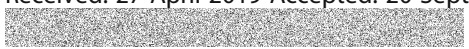

\section{References}

1. Rao RN, Meena LS. Unique characteristic features of Mycobacterium tuberculosis in relation to immune system. Am J Immunol. 2011;7:1-8.

2. Brosch R, Gordon SV, Marmiesse M, Bordin P, Buchrieser C, Eiglmeier K, et al. A new evolutionary scenario for the Mycobacterium tuberculosis complex. Proc Natl Acad Sci U S A. 2002;99:3684-9.

3. WHO. Global tuberculosis report. Geneva: World health organization; 2018.

4. Stepek G, Buttle D, Duce I, Behnke J. Human gastrointestinal nematode infections: are new control methods required? Int J Exp Pathol. 2006;87: 325-41.

5. Brooker S, Kabatereine NB, Smith JL, Mupfasoni D, Mwanje MT, Ndayishimiye $\mathrm{O}$, et al. An updated atlas of human helminth infections: the example of East Africa. Int J Health Geogr. 2009;8:42.

6. Keiser J, Utzinger J. The drugs we have and the drugs we need against major helminth infections. Adv Parasitol. 2010;73:197-230.

7. Haque R. Human intestinal parasites. J Health Popul Nutr. 2007:25:387-91.

8. Mehraj V, Hatcher J, Akhtar S, Rafique G, Beg M. Prevalence and factors associated with intestinal parasitic infection among children in an urban slum of Karachi. PLoS One. 2008;3:e3680.

9. Ayalew A, Debebe T, Worku A. Prevalence and risk factors of intestinal parasites among Delgi school children, North Gondar, Ethiopia. J Parasitol Vector Biol. 2011;3:75-81

10. Blackwell AD, Gurven MD, Sugiyama LS, Madimenos FC, Liebert MA Evidence for a peak shift in a humoral response to helminths: age profiles of lgE in the Shuar of Ecuador, the Tsimane of Bolivia, and the U.S. NHANES. PLoS Negl Trop Dis. 2011;5(6):e1218.

11. Pedersen A, Fenton A. Emphasizing the ecology in parasite community ecology. Trends Ecol Evol. 2006;22:133-9.

12. Elias D, Mengistu G, Akuffo $H$, Britton S. Are intestinal helminths risk factors for developing active tuberculosis? Tropical Med Int Health. 2006;11:551-8.

13. Alemayehu M, Birhan W, Belyhun Y, Sahle M, Tessema B. Prevalence of smear positive tuberculosis, intestinal parasites and their co-infection among tuberculosis suspects in Gondar University hospital and Gondar poly clinic, Northwest Ethiopia. J Microb Biochem Technol. 2014:6:179-84.

14. Alemu G, Mama M. Intestinal helminth co-infection and associated factors among tuberculosis patients in Arba Minch, Ethiopia. BMC Infect Dis. 2017:17:68

15. Dooley KE, Tang T, Golub JE, Dorman SE, Cronin W. Impact of diabetes mellitus on treatment outcomes of patients with active tuberculosis. Am J Trop Med Hyg. 2009;80:634-9.

16. Lonnroth K, Jaramillo E, Williams B, Dye C, Raviglione M. Drivers of tuberculosis epidemics: the role of risk factors and social determinants. Soc Sci Med. 2009:68:2240-6.

17. Cegielski JP, McMurray DN. The relationship between malnutrition and tuberculosis: evidence from studies in humans and experimental animals. Int J Tuberc Lung Dis. 2004:8:286-98.

18. Gupta K, Gupta R, Atreja A, Verma M, Vishvkarma S. Tuberculosis and nutrition. Lung India. 2009;26:9-16.

19. WHO. Guideline: nutritional care and support for patients with tuberculosis. Geneva: World Health Organization; 2013.

20. Alemayehu R, Ahmed K, Sada O. Assessment of knowledge and practice on infection prevention among health care workers at Dessie referral hospital, Amhara region, south Wollo zone, Northeast Ethiopia. J Community Med Health Educ. 2016:6:487

21. WHO. Drug-resistant tuberculosis now at record levels. Geneva: World Health Organization; 2010

22. Birhanu T, Belay M, Ameni G. Molecular characterization of Mycobacterium tuberculosis complex isolated from tuberculous lymphadenitis patients at Dessie private hospitals, northern Ethiopia. JBAH. 2014;4:125-32.

23. Yang Z, Kong Y, Wilson F, Foxman B, Fowler A, Marrs C, et al. Identification of risk factors for extrapulmonary tuberculosis. Clin Infect Dis. 2004;38:199-205 
24. Berg S, Schelling E, Hailu E, Firdessa R, Gumi B, Erenso G, et al. Investigation of the high rates of extrapulmonary tuberculosis in Ethiopia reveals no single driving factor and minimal evidence for zoonotic transmission of Mycobacterium bovis infection. BMC Infect Dis. 2015;15:112.

25. Wright C. Fine-needle aspiration biopsy of lymph nodes. CME. 2012;30:56-60.

26. Tripathi K, Tripathi PC, Nema S, Shrivastava AK, Dwiwedi K, Dhanvijay AK. Modified Petroff's method: an excellent simplified decontamination technique in comparison with Petroff's method. Int J Recent Trends Sci Technol. 2014;10:461-4.

27. Knopp S, Salim N, Schindler T, Karagiannis DA, Rothen J, Lweno O, et al. Diagnostic accuracy of Kato \pm Katz, FLOTAC, Baermann, and PCR methods for the detection of light intensity hookworm and Strongyloides stercoralis infections in Tanzania. Am J Trop Med Hyg. 2014;90:535-45.

28. WHO. WHO physical status: the use and interpretation of anthropometry. Report of a WHO expert committee. Geneva: World Health Organization; 1995.

29. Hanrahan CF, Golub JE, Mohapi L, Tshabangu N, Modisenyane T, Chaisson RE, et al. Body mass index and risk of tuberculosis and death. AIDS. 2010;24:1501-8

30. James W, Norgan N, Bistrian B, Shetty P, Ferro-Luzzi A. The value of arm circumference measurements in assessing chronic energy deficiency in third world adults. Eur J Clin Nutr. 1994;48:883-94.

31. Abrhame T, Haidar J. The sensitivity and specificity of mid-upper arm circumference compared to body mass index in screening malnutrition of adult HIV patients taking ART, evidence from selected facilities of Addis Ababa, Ethiopia. Sci J Public Health. 2014;3:19-24.

32. Alemu A, Kebede A, Dagne B, Amare M, Diriba G, Yenew B, et al. Intestinal parasites co-infection and associated factors among active pulmonary tuberculosis patients in selected health centers, Addis Ababa, Ethiopia: unmatched case control study. BMC Infect Dis. 2019. https://doi.org/10. 1186/s12879-019-4009-0.

33. Mengistu A, Gebre-Selassie S, Kassa T. Prevalence of intestinal parasitic infections among urban dwellers in Southwest Ethiopia. Ethiop J Health Dev. 2014;21:12-7.

34. Endris M, Tekeste Z, Lemma W, Kassu A. Comparison of the Kato-Katz, wet mount, and Formol-ether concentration diagnostic techniques for intestinal helminth infections in Ethiopia. ISIN Parasitol. 2013. https://doi.org/10.5402/ 2013/180439.

35. Deribe K, Meribo K, Gebre T, Hailu A, Ali A, Aseffa A, et al. The burden of neglected tropical diseases in Ethiopia, and opportunities for integrated control and elimination. Parasit Vectors. 2012;5:240.

36. Mama M, Alemu G. Prevalence and factors associated with intestinal parasitic infections among food handlers of southern Ethiopia: cross sectional study. BMC Public Health. 2016. https://doi.org/10.1186/s1288912016-12790-X.

37. Li XX, Chen JX, Wang LX, Tian LG, Zhang YP, Dong SP, et al. Intestinal parasite co-infection among pulmonary tuberculosis cases without human immunodeficiency virus infection in a rural county in China. Am J Trop Med Hyg. 2014;90:106-13.

38. Dargie B, Tesfaye G, Worku A. Prevalence and associated factors of undernutrition among adult tuberculosis patients in some selected public health facilities of Addis Ababa, Ethiopia: a cross sectional study. BMC Nutrition. 2016. https://doi.org/10.1186/s40795-016-0046-x.

39. Dodor EA. Evaluation of nutritional status of new tuberculosis patients at the Effia-Nkwanta regional hospital. Ghana Med J. 2008;42:22-8.

40. Mhimbira F, Hella J, Said K, Kamwela L, Sasamalo M, Maroa T, et al. Prevalence and clinical relevance of helminth co-infections among tuberculosis patients in urban Tanzania. PLoS Negl Trop Dis. 2017;11(2):e0005342.

41. Abate E, Belayneh M, Idh J, Diro E, Elias D, Aseffa A, et al. Asymptomatic helminth infection in active tuberculosis is associated with increased regulatory and Th-2 responses and a lower sputum smear positivity. PLOS Negl Trop Dis. 2015;9(8):e0003994.

42. Adane K, Ameni G, Bekele S, Abebe M, Aseffa A. Prevalence and drug resistance profile of Mycobacterium tuberculosis isolated from pulmonary tuberculosis patients attending two public hospitals in east Gojjam zone, Northwest Ethiopia. BMC Public Health. 2015;15:572.

43. Debebe T, Admassu A, Mamo G, Ameni G. Molecular characterization of Mycobacterium tuberculosis isolated from pulmonary tuberculosis patients in Felege Hiwot referral hospital, Northwest Ethiopia. J Microbiol Immunol Infect. 2014;47:333-8.

44. Kadioglu E, Ucar E, Araz O, Aktas E, Saglam LA. Comparison of two different culture methods for use in the diagnosis of pulmonary tuberculosis. Eur J Med. 2014;46:74-7.
45. Asebe G, Dissasa H, Teklu T, Gebreegizeabhe G, Tafese K, Ameni G. Treatment outcome of tuberculosis patients at Gambella hospital, Southwest Ethiopia: three-year retrospective study. J Infect Dis Ther. 2015;3:211.

46. Bedewi Z, Worku A, Mekonnen Y, Yimer G, Medhin G, Mamo G, et al. Molecular typing of Mycobacterium tuberculosis complex isolated from pulmonary tuberculosis patients in Central Ethiopia. BMC Infect Dis. 2017; 17(1):184.

47. Sinha P, Gupta A, Prakash P, Anupurba S, Tripathi R, Srivastava G. Differentiation of Mycobacterium tuberculosis complex from non-tubercular mycobacteria by nested multiplex PCR targeting IS6110, MTP40 and 32kD alpha antigen encoding gene fragments. BMC Infect Dis. 2016;16:123.

48. Fanosie A, Gelaw B, Tessema B, Tesfay W, Admasu A, Yitayew G. Mycobacterium tuberculosis complex and HIV co-infection among extrapulmonary tuberculosis suspected cases at the university of Gondar hospital, northwestern Ethiopia. PLoS One. 2016;11(3):e0150646.

49. Korma W, Mihret A, Hussien J, Anthony R, Lakew M, Aseffa A. Clinical, molecular and drug sensitivity pattern of mycobacterial isolates from extrapulmonary tuberculosis cases in Addis Ababa, Ethiopia. BMC Infect Dis. 2015;15:456.

50. Forssbohm M, Zwahlen M, Loddenkemper R, Rieder H. Demographic characteristics of patients with extrapulmonary tuberculosis in Germany. Eur Respir J. 2008;31:99-105.

51. Peto $H$, Pratt $R$, Harrington $T$, LoBue P, Armstrong L. Epidemiology of extrapulmonary tuberculosis in the United States, 1993-2006. Clin Infect Dis. 2009:49:1350-7.

52. Noertjojo K, Tam C, Chan S, Chan-Yeung M. Extra-pulmonary and pulmonary tuberculosis in Hong Kong. Int J Tuberc Lung Dis. 2002;6:879-86.

53. Biadglegne F, Tesfaye W, Anagaw B, Tessema B, Debebe T, Anagaw B, et al. Tuberculosis lymphadenitis in Ethiopia. J Infect Dis. 2013;66:263-8.

\section{Ready to submit your research? Choose BMC and benefit from:}

- fast, convenient online submission

- thorough peer review by experienced researchers in your field

- rapid publication on acceptance

- support for research data, including large and complex data types

- gold Open Access which fosters wider collaboration and increased citations

- maximum visibility for your research: over $100 \mathrm{M}$ website views per year

At BMC, research is always in progress.

Learn more biomedcentral.com/submissions 